\title{
Sex Determination From The Upper End And Length Of The Femur: A Morphometric Study
}

\author{
Authors \\ Dr Savita Takale ${ }^{1}$, Dr Gopal Bagal ${ }^{2}$ \\ ${ }^{1}$ Associate Professor, CSMSS, Ayurvedic Medical College, Aurangabad, Maharashtra, India-434000 \\ ${ }^{2}$ Associate Professor, ACPM Medical College, Dhule, Maharashtra, India-424001 \\ Corresponding Author
}

Dr Gopal Bagal

Associate Professor, Dept of Anatomy, ACPM Medical College, Sakri Road, Dhule, MH, India-424001

Email:drgopalbagal@gmail.com

\begin{abstract}
Identification of sex from skeleton is an important demographic assessment in medicolegal investigation. Determination of sex is relatively easy if the entire skeleton is available for examination. Even when skull and pelvis, the most reliable bones for sex determination are available not more than $98 \%$ of accuracy can be achieved in identifying the sex. Often in medicolegal cases it is expected to determine sex from isolated long bones or their fragments from the crime site in order to establish a possible identity.

Assessment of sex from femoral dimensions has been tried before in several populations. Studies conducted so far have demonstrated that populations differ from one another in size and proportion. The anatomical knowledge of different dimensions of femur specially head and neck of the femur is very essential in anthropological and medicolegal practice for sex determination and as well as to radiologists, rheumatologists and orthopedic surgeons for diagnosis and planning of fragment.

This is an observational descriptive study carried out in the Department of Anatomy. The present study was performed on one hundred (50-Male \& 50-Female) left sided fully ossified human femur bones collected from the Department of Anatomy and from the medical students. Morphometric study was carried on all samples by direct physical method. There was statistically significant difference found in the diameter of the head and neck and length of the femur bones between male and female bones.

KEY WORDS: Human femur, Head and Neck diameter, Length of femur, Sexual variations.
\end{abstract}

\section{INTRODUCTION}

The femur is the longest and strongest bone of the human body. Morphologically it is a typical long bone. The upper part of the femur forms the hip joint with the pelvis and the lower part of the femur forms the knee joint with the tibia. It forms the skeleton of the thigh, bears body weight in erect posture, form blood cells and acts as store house for calcium and phosphate.
The anatomical knowledge of human sex from skeletal part is of particular importance in forensic osteology and it relies heavily on the up to date techniques in order to provide accurate information to medicolegal system. With time the assessment has a shift from visual analysis to anthropometric measurements which when processed through modern statistical techniques 
has made sex determination more objective. Sex determination is relatively easy if the entire skeleton is available, pelvis and skull are more reliable bones for this purpose ${ }^{(1)}$.

Sex can be determined with $100 \%$ accuracy when entire skeleton is available. As the femur is composed of hard tissue, they are the best preserved part of skeleton after death and in many times they are the only available parts for forensic examination ${ }^{(2)}$. In clinical practice dislocation of the hip joint and fracture neck of the femur is very common. The knowledge about different diameter of the head and neck of the femur is essential in orthopedic surgery in prosthesis and nail application and for radiological practice in identifying pathology of bone and also for determining age. The femoral normative values are also essential to plastic and reconstructive surgeons in their reconstruction and medical rehabilitation.

Morphological and stastistical analysis of femoral anthropometry among different population reveals a great amount of variation. Femoral anthropometric measurements from different countries are likely to be affected by racial variations in diet, heredity, climate and other geographical factors related to life style ${ }^{(3)}$. India is a vast country with a number of different populations but only a few studies pertaining to femur are available from this part of the world. Therefore, in the present study, femur was studied for sex determination in the population of North Maharashtra and Marathwada region.

\section{MATERIAL AND METHODS}

The present study was conducted on 100 femora of left side (50-male \& 50-female) in the Department of Anatomy. Bones were collected from the Department of Anatomy as well as from the $1^{\text {st }}$ and $2^{\text {nd }}$ year medical students. The reason for choosing left side for femur is based on the reported observation that left lower limb is functionally dominant in majority of human beings ${ }^{(4)}$. All these bones belonged to people from North Maharashtra and Marathwada region.
Five measurements were taken. These measurements were taken using the digital vernier caliper and osteometric board. The following measurements were taken

1. Maximum vertical diameter of head

2. Maximum transverse diameter of head

3. Minimum vertical diameter of neck

4. Minimum transverse diameter of neck

5. Maximum length - from the head to the medial condyle measured with an osteometric board.

All the measurements were recorded in $-\mathrm{mm}$.

\section{Measurements of vertical diameter of head of the femur}

The fixed jaw of the digital slide caliper was placed on the superior surface and the sliding jaw was placed on the inferior surface of the head of the femur, and three readings were taken between different points. The maximum reading was selected and recorded as vertical diameter of head of the femur.

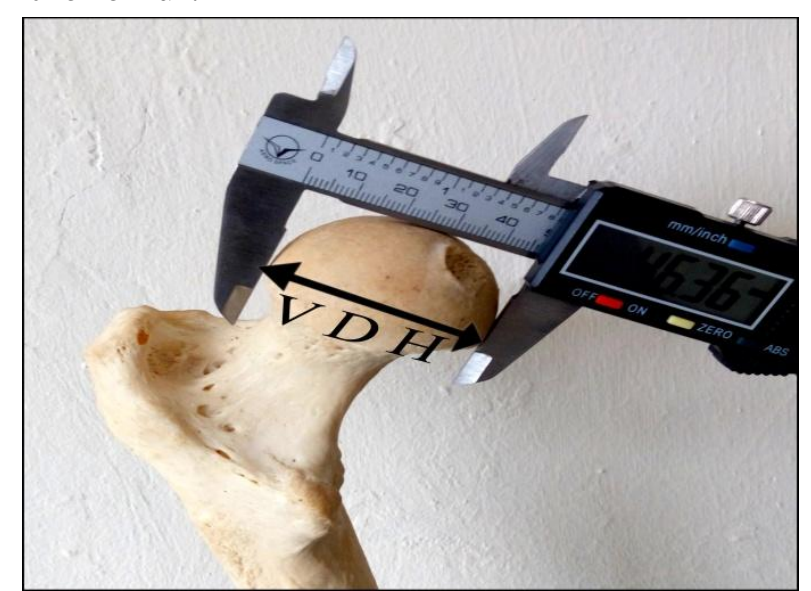

Fig.1. Measurement of vertical diameter of head (VDH) of the femur

\section{Measurements of transverse diameter of head of the femur}

The fixed jaw of the digital slide caliper was placed on the posterior surface and the sliding jaw was palced on the anterior surface of the head of the femur, and three readings were taken between different points. The maximum antero-posterior reading was selected and recorded as transverse diameter of head of the femur. 


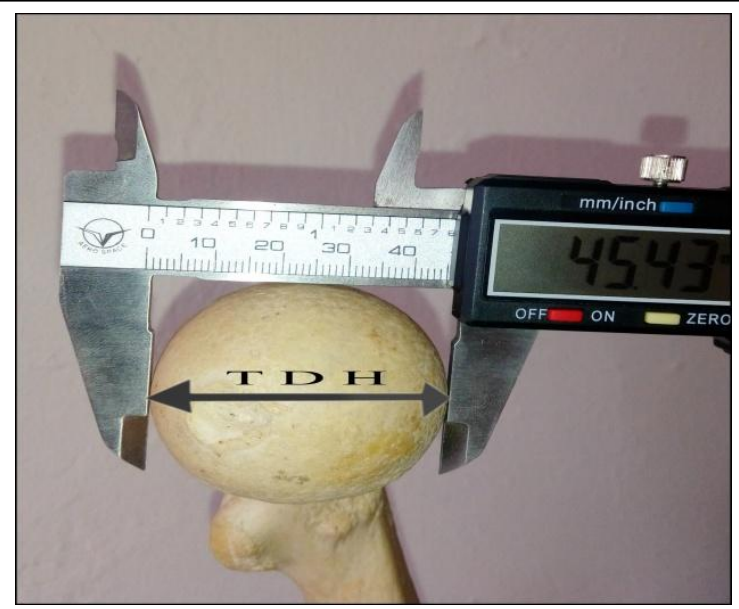

Fig.1. Measurement of transverse diameter of head (TDH) of the femur

\section{Measurements of vertical diameter of neck of the femur}

The fixed jaw of the digital slide caliper was placed on the superior surface and the sliding jaw was palced on the inferior surface of the neck of the femur, and three readings were taken between different points. The minimum reading was selected and recorded as vertical diameter of head of the femur.

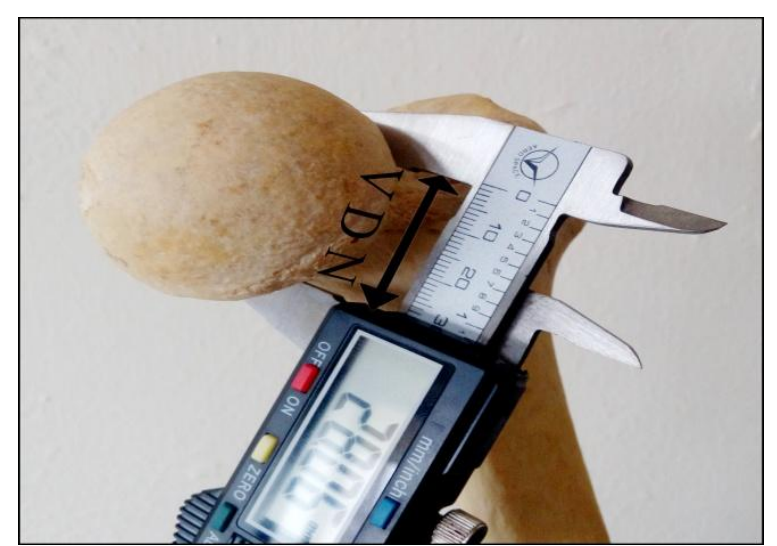

Fig.3. Measurement of vertical diameter of neck (VDN) of the femur

\section{Measurements of transverse diameter of neck of the femur}

The fixed jaw of the digital slide caliper was placed on the posterior surface and the sliding jaw was placed on the anterior surface of the neck of the femur, and three readings were taken between different points. The minimum antero-posterior reading was selected and recorded as transverse diameter of neck of the femur.

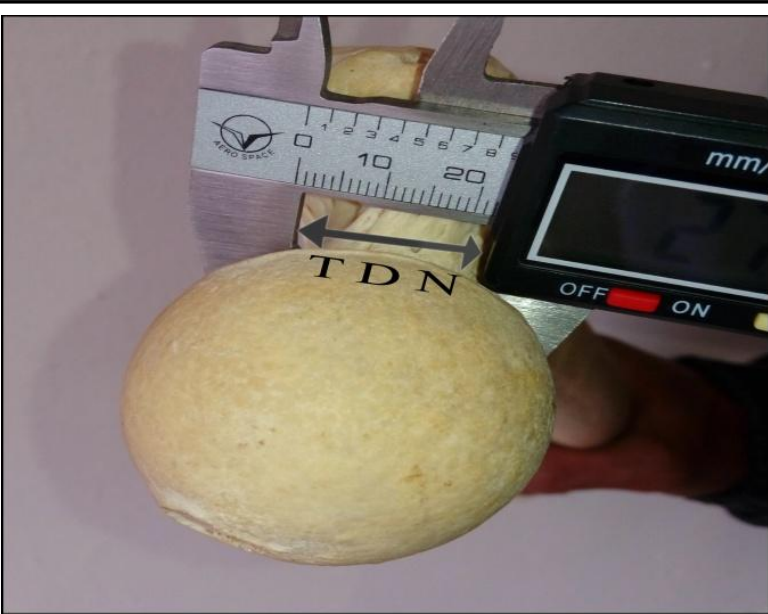

Fig.4. Measurement of transverse diameter of neck (TDN) of the femur

\section{OBSERVATIONS \& RESULTS}

In the present study, the mean $( \pm \mathrm{SD})$ value of vertical diameter of head $(\mathrm{VDH})$ of the femur bones of left side were $46.03 \mathrm{~mm}$ in male and $41.84 \mathrm{~mm}$ in female. There was a significant difference in between male and female bones in vertical diameter of head.

The mean $( \pm$ SD) value of transverse diameter of head (TDH) of the femur bones of left side were $44.93 \mathrm{~mm}$ in male and $40.58 \mathrm{~mm}$ in female. There was a significant difference in between male and female bones in transverse diameter of head as shown in table no.1.

The mean $( \pm S D)$ value of vertical diameter of neck (VDN) of the femur bones of left side were $31.95 \mathrm{~mm}$ in male and $29.54 \mathrm{~mm}$ in female. There was a significant difference in between male and female bones in vertical diameter of neck.

The mean $( \pm$ SD) value of transverse diameter of neck (TDN) of the femur bones of left side were $25.98 \mathrm{~mm}$ in male and $24.79 \mathrm{~mm}$ in female. There was a significant difference in between male and female bones in transverse diameter of neck as shown in table no 1.

The length of the femoral shaft evaluated in this study showed a mean of $480.8 \mathrm{~mm}(48.08 \mathrm{~cm})$ in male and $440.4 \mathrm{~mm}(44.04 \mathrm{~cm})$ in female. 
Table 1. Vertical and transverse diameter of head and neck $\&$ length of the femur in male and female

\begin{tabular}{|c|c|c|c|c|c|}
\hline \multirow[b]{2}{*}{ Sex } & \multicolumn{2}{|l|}{ Head } & \multicolumn{2}{|l|}{ Neck } & Length \\
\hline & $\begin{array}{l}\text { Vertical Diameter } \\
\text { (VDH) } \\
(\mathrm{mm})\end{array}$ & $\begin{array}{l}\text { Transverse Diameter } \\
\text { (TDH) } \\
(\mathrm{mm})\end{array}$ & $\begin{array}{l}\text { Vertical Diameter } \\
\text { (VDN) } \\
(\mathrm{mm})\end{array}$ & $\begin{array}{l}\text { Transverse Diameter } \\
(\mathrm{TDN}) \\
(\mathrm{mm})\end{array}$ & (cm) \\
\hline Male & $\begin{array}{l}46.03 \\
(40.05-46.41)\end{array}$ & $\begin{array}{l}44.93 \\
(37.95-46.50)\end{array}$ & $\begin{array}{l}31.95 \\
(29.15-32.60)\end{array}$ & $\begin{array}{l}25.98 \\
(21.80-26.90)\end{array}$ & $\begin{array}{l}48.08 \\
(45-51)\end{array}$ \\
\hline Female & $\begin{array}{l}41.84 \\
(37.64-42.61)\end{array}$ & $\begin{array}{l}40.58 \\
(36.0-42.74)\end{array}$ & $\begin{array}{l}29.54 \\
(20.05-26.00)\end{array}$ & $\begin{array}{l}24.79 \\
(26.09-29.80)\end{array}$ & $\begin{array}{l}44.04 \\
(40-47)\end{array}$ \\
\hline
\end{tabular}

Demarketing points from the above results calculated that is the measurement above which no female bone can be found and below which no male femora can be found. So, demarketing points for various parameters found in our studies are shown in table 2.

Table 2. Demarketing points calculated for various parameter in this study

\begin{tabular}{|l|l|l|l|l|l|}
\hline \multirow{3}{*}{ Sex } & \multicolumn{5}{l}{ Demarketing points } \\
\cline { 2 - 6 } & VDH(mm) & TDN $(\mathrm{mm})$ & VDN $(\mathrm{mm})$ & TDN $(\mathrm{mm})$ & Length $(\mathrm{cm})$ \\
\hline Male & $>42.61$ & $>42.74$ & $>29.80$ & $>26.00$ & $>47$ \\
\hline Female & $<40.05$ & $<37.95$ & $<29.15$ & $<21.80$ & $<45$ \\
\hline
\end{tabular}

Using demarketing points sex of the bone can be determined. Bones with demarketing points above $42.61 \mathrm{~mm}$ (VDH), $42.74 \mathrm{~mm}$ (TDH), $29.80 \mathrm{~mm}$ (VDN), $26.00 \mathrm{~mm}$ (TDN) \& $47 \mathrm{~cm}$ (Length) can be correctly classified as male bones.

Simillarly, bones with demarketing points below $40.05 \mathrm{~mm}$ (VDH), $37.95 \mathrm{~mm}$ (TDH), $29.15 \mathrm{~mm}$ (VDN), $21.80 \mathrm{~mm}$ (TDN) \& 45cm (Length) can be correctly classified as female bones.

\section{DISCUSSION}

Sex determination from long bones or their fragments is often required to establish a possible identity. It is a common experience for the forensic expert to be confronted with poorly preserved or fragmentary bones. Due to tubular structure of long bones, they are often better preserved than other shorter bones. Thus data for long bone measurements will be more useful. In an Indian study from central India maximum diameter of head gave the best accuracy $(90.4 \%)$ (4). In the present study also the best accuracy was achieved by maximum diameter of head $(83 \%)$ when applied singly. This is in contrast with Chinese, Thai, and South African whites where the most dimorphic parameter was epiphyseal breadth ${ }^{(5)}$. A number of studies have shown that combination of variables give better accuracy for sex determination. Racial differences have been shown to exist in the dimensions of femoral heads from studies carried out by various authors.

Felts believed that the gross shape of long bones was caused by intrinsic factors, while the specific details were determined by the bone adaptation to the functional environment ${ }^{(6)}$. The average diameter of the head of the femur is therefore different in different races. Parsons showed that if the vertical diameter of the head of the femur was greater than $48 \mathrm{~mm}$, the bone belonged to a male and when below $44 \mathrm{~mm}$, it indicated a female bone ${ }^{(7)}$. For the Indian femora, Singh and Singh reported figures above $45.5 \mathrm{~mm}$ for a male bone and less than $41.5 \mathrm{~mm}$ for a female bone ${ }^{(8)}$. Hashimoto using the antero-posterior diameter for sex determination reported an average of 46.80 $\mathrm{mm}$ for Chinese femora ${ }^{(9)}$. Studies in Nigerian used both diameters to determine sex employing identification and demarcating points ${ }^{(10)}$. In a black Malawians study it was found that the vertical and transverse femoral head diameters for males were significantly greater than the corresponding values for females. This is an indication that femoral head diameters could be used for sex differentiation among Black Malawians ${ }^{(11)}$. The values of male right and left transverse and vertical diameters for Malawians, 
though greater than those of females, were, however, relatively lower than those of south eastern. This differentiation could be explained on factors like diet, genetic and climatic conditions.

The mean vertical and transverse diameters of head and neck of the femur and also the length of the femur found in this study were somewhat similar to other studies like North Indian, Central Indian, Gujrat, Thailand ${ }^{(12)}$ and Chinese ${ }^{(13)}$. The similarity of food habit may predispose to the same growth pattern of femur of these populations. Low values of these dimensions were found in South Indian population, because they are vegetarian and lack protein in their diet. This may be the reason for their low dimension.

\section{CONCLUSION}

The present study was an attempt to construct data on different dimension of adult femur and sexual variations in Indian population. The knowledge about different diameter of the head and neck of the femur is essential in orthopedic surgery in prosthesis and nail application and for radiological practice in identifying pathology of bone and also for determining age. Morphometric data of femur might help a doctor or nutritionist for calculating body energy need of a normal individual or to identify malnourished cases. So this type of study has a vital role in anatomy, forensic science, radiology, orthopedic surgery, plastic surgery, medical rehabilitation, sport science and nutrition science.

\section{REFERENCES}

1. DiBennardo R, Taylor JV. Classification and misclassification in sexing the black femur by discriminant function analysis. American Journal of Physical Anthropology.1982: 58: 145-151.

2. Gunay Y, Altinkok MT. The value of the size of foramen magnum in sex determination. Journal of Forensic Science. 2000: 7: 147-149.
3. Bokaria P, Kothari R, Waghmare JE. Anthropometric study of femur in central Indian population. J MGIMS. 2009: 14(2): 47-49.

4. Dogra SK, Singh J. Asymmetry in bone weight in human lower limbs. J. Anat. Anz. Bd. 1971: 128: 278-280.

5. Soni G, Dhall U, Chhabra S. Determination of sex from femur: Discriminative analysis. J. Anat Soc India. 2010: 59(2): 216-221.

6. Felt WJ. Transplantation studies of factors in skeletal organogenesis. Amer J Phy Anthropol. 1959: 17: 201-215.

7. Parsons FG. The character of English thigh bone: The difficulty of sexing. J. Anat. 1994: 49: 335-361.

8. Singh SP, Singh S. The sexing of adult femora: Demarcating points for Varanasi zone. 1972: 11: 45-49.

9. Hashimoto M. Ethnologic studies on Chinese. J. Oriental Med. 1938: 110: 479484.

10. Nwoha PU. Femoral head diameters in Nigerians. African J Med Sci. 1990: 19: 157-161.

11. Igbigbi PS, Msamati BC. Sex determination from femoral head diameters in Black Malawians. 2000: 77(3): 147-151.

12. King CA, Iscan MY, Loth SR. Metric and comparative analysis of sexual dimorphism in the Thai femur. J. Forensic Science. 1998: 43(5): 954-958.

13. Iscan MY, Shihai D. Sexual dimorphism in the Chinese femur. Forensic Science International. 1995: 74(2): 79-84. 